\title{
IMPLEMENTING AUGMENTED REALITY SANDBOX IN GEODESIGN: A FUTURE FOR GEODESIGN
}

\author{
A. Afrooz ${ }^{1 *}, \mathrm{H}$. Ballal ${ }^{2}$, C. Pettit ${ }^{1}$ \\ ${ }^{1}$ Faculty of the Built Environment, The University of New South Wales, Sydney, Australia - (a.eslamiafrooz, c.pettit)@unsw.edu.au \\ ${ }^{2}$ Managing Director at Geodesignhub Pvt. Ltd.- (hrishi@geodesignhub.com)
}

Commission VI, IV/9

KEY WORDS: Geodesign, Augmented Reality sandbox, 3D modelling, trail design

\begin{abstract}
:
Geodesign method and tools are extensively used for collaborative decision making focused on different fields such as transportation, land use, and landscape and has been applied in various places around the world. Nowadays, Augmented Reality (AR), Virtual Reality (VR) and more recently AR sandbox are increasingly becoming very popular particularly as a pedagogical tool. This research aims to investigate whether an AR sandbox could enhance the understanding of people around the development of design proposals and their impacts. We explored if AR sandbox could be implemented in a collaborative geodesign workflow. We reported an experiment where people were asked to build new trails using the sandbox and how the trails they designed were integrated with a larger design. Results explore opportunities and limitations of implementing AR sandbox in a collaborative geodesign workflow based on the experiment in this paper. Our AR sandbox experiment revealed a wide range of benefits to participants in the trail planning and to the geodesign structure.
\end{abstract}

\section{INTRODUCTION}

\subsection{Introduction}

The integration of the design process with new technology has been advocated by a group of scholars and technologists including Bill Miller, an architect and engineer at ESRI and Carl Steinitz, an urban designer professor at Harvard University (ESRI 2010). The origins of geodesign dates back to 1960s with the publication of "Design with nature" by McHarg (1969) (Haddad 2015). Steinitz proposed many ideas and he defined geodesign as “changing geography by design” (Steinitz 2012).

Geodesign is a "methodology" that provides a design framework (Steinitz 2012). Steinitz (2012) defined geodesign as "a set of concepts and methods that are derived from both geography and other spatially oriented sciences, as well as from several of the design professions, including architecture, landscape architecture, urban and regional planning,...” (p.1). In other words, geodesign is based on geographic sciences, and interactions and negotiations between professionals and the people of the place. It is based on data, analysis, and design (Miller 2012).

On the one hand, there are many visualisation techniques to support place based analysis (Pettit et al. 2012). In recent times we are seeing a growing body of research and development in Augmented Reality (AR), and Virtual Reality (VR) in the context of city planning and design (Jiang et al. 2018).

On the other hand, there are many forms of thinking such as verbal, hypothetical, statistical and so on. In science or any field multiple forms of thinking are being used. Spatial thinking is one form of thinking and is a collection of cognitive skills (National Academies Press (U.S.) 2006). However, spatial thinking - a form of human cognition which can be used in reading urban planning and architectural blueprints (Liben 2007) - is usually challenging for people. Due to this reason different laboratories around the world are utilizing AR sandbox to allow students to be quickly immersed in the learning process through a more intuitive approach. This innovative 3D visualisation technique and real-time augmented user interface proved to allow students to understand and create the real world in urban planning and design (Petrasova et al. 2015) hydrology (Petrasova et al. 2015), geoscience (Kreylos et al. 2016) and geography (Jenkins et al. 2014) in visualising and analysing different themes such as flooding hazards, soil erosion, watershed development, viewshed analysis, coastal modelling and trail planning (Petrasova et al. 2015).

This study is one of the first empirical studies that is concentrated on the implication of the AR sandbox in geodesign structure. Looking at an example of geodesign workshop in Sydney, Australia (Pettit et al. 2017) this paper attempts to bring a more intuitive approach in engaging participants in future geodesign workshops by proposing Augmented Reality (AR) sandbox. Geodesignhub and AR sandbox are tools that provide support to planning and visioning processes. One of the goals for this research was to test the effectiveness of these tools in comprehension and the quality of interventions developed. We are interested in the application of AR sandbox as a tool to help people better understand and engage in place based design. Accordingly, the focus of the paper is on the role of AR sandbox as an interface to various components of the geodesign process. In other words, this paper is proposing and evaluating an AR Sandbox visualisation approach for supporting the geodesign collaborative approach which could be used in future geodesign workshops. The main reason for using tools like Geodesignhub and AR Sandbox are to help the participants develop a deeper understanding of the problems, the design tradeoffs. These tools provide intuitive interfaces to enable interactions. The primary objective was not to do advanced

\footnotetext{
* Corresponding author
} 
spatial analysis (although it is possible to do given the digital nature of these tools) but to invite the participants to negotiate about the future of the place.

To investigate the aim of the study, two geodesign systems focusing on (i) tourism and (ii) active transport are selected from the completed Sydney Botany Bay Geodesign workshop (Pettit et al. 2017). An experiment was designed, with participants tasked with building new "trails or pathways" for the fore mentioned two systems. Although trail design is a product of expert knowledge and site surveying, spatial thinking support through geospatial modelling can be used for this purpose (Petrasova et al. 2015).

This paper is organized in five parts. First, it describes the geodesign workflow and framework, and the AR sandbox. Second, in methods section, we provide background material on a study area from the first geodesign workshop in Australia which was held in Sydney 2016. A case study is selected within the previous study area and an experiment is conducted for this area which is known as "Malabar headlands". Participant profiles and the process of the experiment are explained in this section. Third, results of the online questionnaire are described. Fourth, a discussion of the findings is presented. We propose as to where in the geodesign framework AR sandbox integration can be useful and supportive. The capabilities and limitations of the AR sandbox resulted from the trail planning experiment are explained in this section. Finally, conclusions and recommended future research directions are outlined.

\section{LITERATURE REVIEW}

The geodesign framework is described in this section and later in the paper (in Sections 4 and 5) is compared with the results of the experiment to develop the conceptual framework of this paper. In addition, AR sandbox and its applications in similar projects are reviewed.

\subsection{Geodesign}

In 2015, the "Steinitz framework" was transformed into its digital representation through a software that enables a digital design workflow and it was tested in several workshops. (Rivero et al. 2015; Ballal 2015; Nyerges et al. 2016). Geodesignhub (Ballal n.d.) is a software platform where most of this analytical thinking and collaboration approach takes place. Geodesignhub is a cloud-based collaboration platform which has been designed for carrying out projects to address decision making in the context of complex geo-strategy problems. The software has been used to manage sites in diverse contexts: marine management, tourism development and so on. In this case it was used in the context of urban design. It is often used in the form of an interactive hands-on workshop meeting (Pettit et al. 2017).

What makes geodesign with geodesignhub unique is the process of creation of a collaborative design using the Steinitz framework (Steinitz 2012). The workflow guides the participants through a series of steps to facilitate negotiations using software support to compare the interventions. Geodesignhub embodies the systems-based approach to design where the design problem is broken down in to constituent systems or themes. The participants initially design exclusively in different "systems" such as high-density housing, low density housing, active transport, tourism, and so on, then synthesizes the designs. Afterwards, they negotiate and come up with one or a set of interventions as the best and final design options. This collaborative process is supported by software in 2D; however, in some cases 3D modelling of the final negotiation plan can be prepared using JavaScript and/or CityEngine using API connections (an example of Sydney workshop 2016).

Steinitz (2012) proposed a comprehensive framework for geodesign. The framework asks six questions and has six corresponding models as follow:

1. "How should the study area be described?” (Representation models);

2. "How does the study area operate?” (Process models);

3. "Is the current study area working well?" (Evaluation models);

4. "How might the study area be altered?” (Change models);

5. "What differences might the changes cause?" (Impact models); and

6. "How should the study area be changed?" (Decision models) (Steinitz 2012).

Each of the abovementioned iterations is based on a loop diagram followed by six new questions, concepts, and graphs. Representation model helps geodesign study to identify the minimum required and relevant data. It also considers how change will be visualized. Understanding the processes that are involved in geographic change helps to identify the required data for a geodesign study. Process model can range from direct process models, to more complex such as temporal ("what if?"), adaptive ("from what to what?") and behavioural ("from whom/where to whom/where?”) (Steinitz 2012). Geodesign heavily relies on evaluation maps (Steinitz 2012). The concept of evaluation models is derived from decision models and will directly influence the change model because the design needs to focus on the areas that need change or need to be conserved. Evaluation models can evaluate the characteristics of the environment qualitatively. One key challenge of the change model is to get from present to the best possible future. Change has four phases including vision, strategy, tactics, and actions (Steinitz 2012). Impact model assesses the benefits and costs of the changes quantitatively. Impact models have to be assessed in different ways usually with a set of models such as economics and environmental impact assessments. Finally, decision model is where decisions are made based on the cultural, personal, and institutional knowledge of the decision makers.

The evaluation and change models are the two models that the research team assume AR sandbox can play an important role for participants to understand their designs. This will be examined further in this paper.

\subsection{Augmented Reality Sandbox}

The AR sandbox was first developed by UC Davis, California as a result of a NSF-funded project with the aim of teaching earth science concepts (UC Davis 2016). It displays a dynamic topographic map which composes of a box containing real sand, a projector, and a Microsoft Kinect 3D camera which can be connected to a computer system.

The sand is overlain by the digital projection of the contour lines and colour elevation map. Data can be send through the Microsoft Kinect 3D camera into either Ubuntu (system 76 2018; UC Davis 2016) or GrassGIS (NCSU GeoForAll Lab 2016) and into a software program that displays the information 
onto the sand through the projector. The user can manipulate the sand and simultaneously observe the real time changes of the elevation map and the contour lines projected onto the sand. In other words, the user shapes the real sand which is then augmented in real time by contour lines, elevation colour maps, and simulated water. By holding the hands under the Kinect 3D camera, the user can add virtual water to the surface of the sand flowing over the real surface of the sand with real-time water simulation (Kreylos et al. 2016).

More than 150 laboratories all around the world are installing and using AR sandbox in various fields in both education and practice (Kreylos et al. 2016). AR sandbox can teach many geographic concepts to users such as reading and interpreting contour lines and topographic maps, flooding and formation of watershed and can also be used in field trip preparation and trail planning (Kreylos et al. 2016).

In a trail planning and sandbox study, Petrasova et al. (2015) utilized tangible landscape (NCSU GeoForAll Lab 2016) to calculate the optimized route between some way points. They computed the least cost route between a selected numbers of waypoints considered a specific slope value, construction cost, aesthetics and view using network analysis, GrassGIS (GRASS GIS 2018). Similar to Petrasova et al. (2015), in the design of this study, slope degree has been calculated and some selection criteria for waypoints have been considered in selecting the case study such as aesthetic and environmental variables.

\section{METHODS}

This section describes the Botany Bay Geodesign workshop followed by the design of the AR sandbox experiment. The progress and purpose of the workshop have been published in (Pettit et al 2017). This section summarises the output of the workshop that are required for the current paper.

\subsection{Botany Bay geodesign workshop}

The workshop was held from $1^{\text {st }}$ to $2^{\text {nd }}$ December 2016 at Sydney, Australia. A public lecture was given by Prof. Carl Steinitz on the $30^{\text {th }}$ November 2016 as a briefing for the geodesign workshop. It included an overview of geodesign framework with several examples from previous workshops. A number of 30 professionals were participated the workshop. Participants had various professional backgrounds from different governmental and private sectors: local councils including Randwick City Council, City of Botany Bay Council, and Waverley Council, the greater Sydney Commission, Sydney Water, Land and housing corporation, Transport for New South Wales, department of planning NSW, Urban Growth, University of New South wales, and University of Canberra, and private companies such as Ernst and Young (EY) and Arup. Participants were briefed of the case study (Figure 1), objectives of the workshop and the Sydney 2050 projections.

Geodesignhub provides critical functionalities to enable collaborative design and negotiations. The participants have to go through three primary processes (all done together in public):

- Review existing conditions and draw ideas for improving it using simple diagrams

- Get grouped in different teams where they pick specific diagrams they prefer

- Compare contrast the selections form alliances and negotiate.

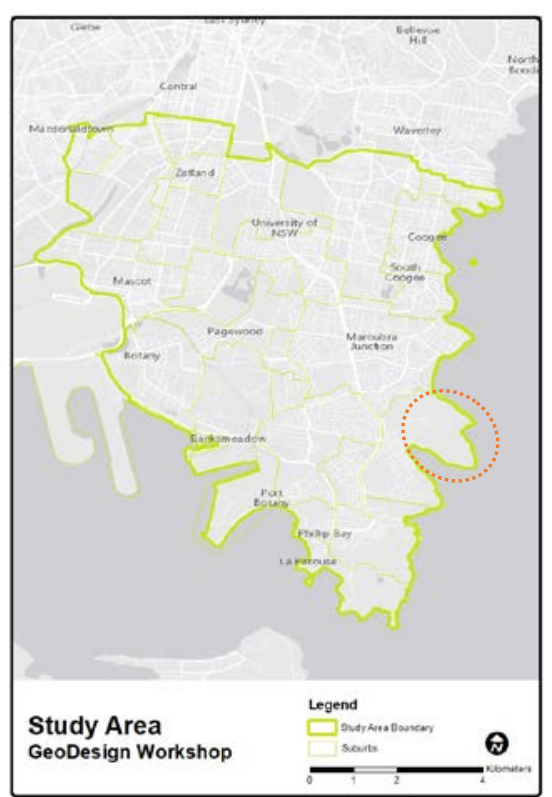

Figure 1. Study area of the geodesign workshop, Sydney December 2016; The case study of the sandbox experiment is displayed in circle (in red)

Participants were using the Geodesignhub (Ballal n.d.) to draw diagrams (i.e. simple polygons illustrating the location of the project or policy) representing the proposed projects and policies which were agreed between team members (Figure 2). They were briefed on how to log in and use this online platform and each team was equipped with one person with geodesign experience.

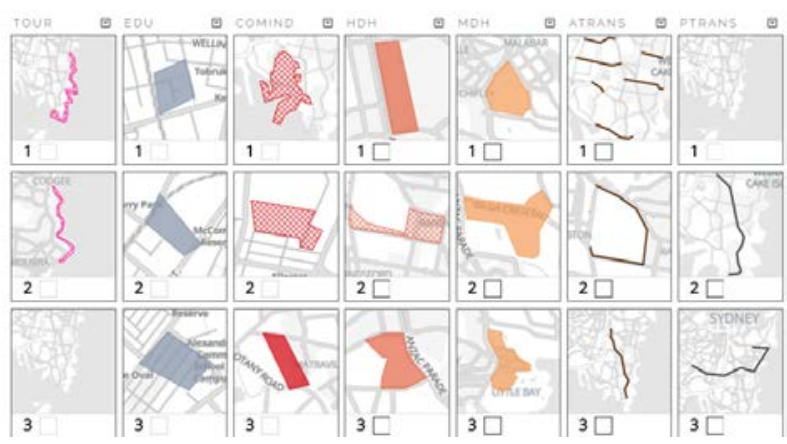

Figure 2. An example of the projects and policies that participants have created during the workshop using geodesignhub (Ballal n.d.)

The workshop was run in two phases: a) scoping, data collection, and analysis; at this stage data was collected from relevant organization, and was assessed with the consultation of the participated organizations; and b) implementation; participants were involved at this stage (Pettit et al. 2017). As the result of phase 1 , nine systems were identified including: medium density housing, high-density housing, commerce and industry, public transport, active transport, green infrastructure, blue infrastructure, education, and tourism. Participants were first divided into nine groups each focusing on one system. They were then divided into six multidisciplinary teams for working on specific development scenarios. After evaluating their design concepts (i.e. scenario design), participants were presented their work and after negotiations across teams, they came up with the final version of the scenario design (see Pettit et al. 2017). 
Due to the limitations of assessing the entire workshop, only two systems of tourism and active transport were selected from this workshop to be further examined with AR sandbox as a trial in this paper.

\subsection{Augmented Reality Sandbox experiment}

3.2.1 Case study: The case study was selected from the geodesign workshop as a site with different steep and evaluation with potential opportunities for future tourism and active transport system. The site was intentionally selected closer to the coastal area for this paper to allow participants study the erosion and other environmental sensitivity factors such as flooding. This site is located at Sydney's east between Malabar and Maroubra beaches. There exist scenic coastal walkways in the Sydney's east. Malabar coastal walkway has been recently opened to public. It is also known as Malabar headland national parks. The elevation and contour lines of the case study are shown in Figure 3.

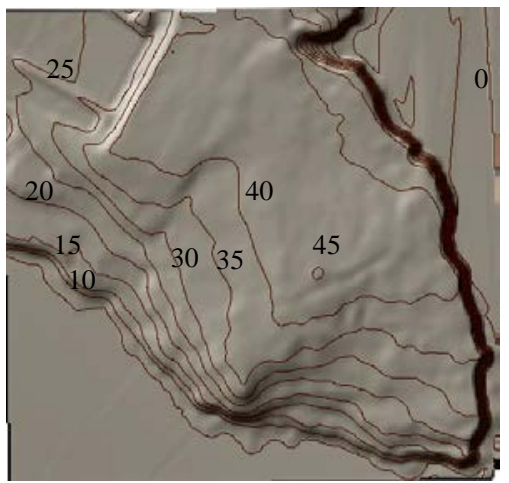

Figure 3. Hillshade illustration of the case study for the AR sandbox experiment. Contour line values are displayed.

3.2.2 Participants: Four participants voluntarily attended this experiment. The corresponding author disseminated the recruitment email to the faculty of built environment HDR students. Four PhD students were recruited for this experiment based on their available time, experience, knowledge, and willingness to participate. Two participants were at each group of tourism and active transport. Participants were $\mathrm{PhD}$ students at the faculty of Built Environment, UNSW Sydney Australia with professional expertise in either of the following fields of study including: urban planning, urban design, architecture, and/or landscape architecture (age range 35-44).

3.2.3 Process: The AR sandbox experiment included 2 phases: Scenario design and Sandbox (Figure 4). The experiment took place at the City Analytics Lab (CAL), UNSW (UNSW Built Environment 2018) in April 2018. Multi-touch screen cruiser tables were used for the phase 1 of the experiment and the Augmented reality (AR) sandbox was utilized to facilitate the design of the phase 2 (Figure 5).
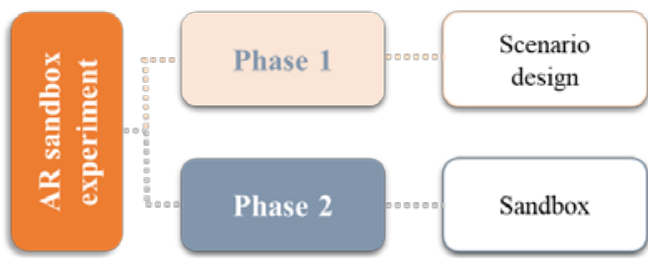

Figure 4. The AR sandbox geodesign experiment

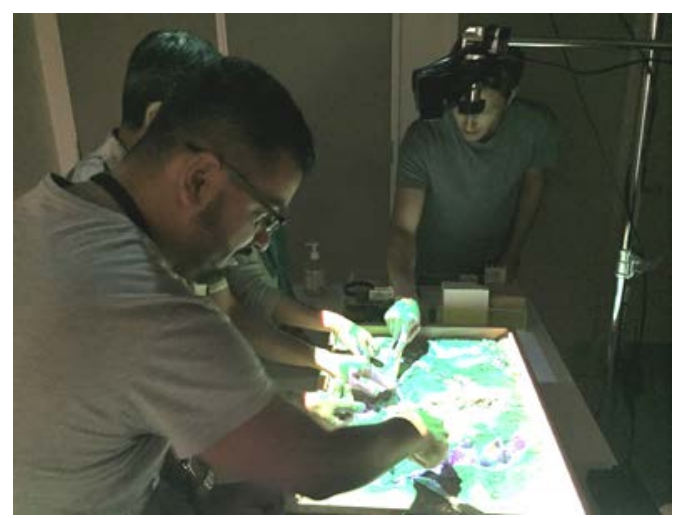

Figure 5. Participants using the sandbox

AR sandbox was comprised of a box filled with kinetic sands, 3D scanner (Microsoft Kinect 3D camera Xbox360), a projector (Optoma ML 750 LED 700 Lumens), and a laptop (System 76, Ubuntu Linux). Kinetic sands were used for its adhesiveness and moldability to sculpt models. 3D scanner captures changes from distance to the sand surface. Using Ubuntu system, we processed data using the commands originally developed by Oliver Kreylos (Kreylos 2018a) of the University of California - Davis open-source software available at (system 76 2018). The software also project water flow simulation by holding the hands under the 3D scanner or by assigning a keyboard to the water flow simulation. For the purpose of this experiment, GrassGIS (GRASS GIS 2018) was also used to project the contour lines as well as the evaluation map of the tourism system resulted from the geodesign workshop onto the sands.

Phase 1 was named scenario design (Figure 6). Participants were briefed on geodesign process and were given the evaluation map of the site which was resulted from the geodesign workshop (Figure 7). Evaluation map or site assessment maps are simple red/yellow/green maps that inform participants where they can build and where they should be careful (Ballal 2017).

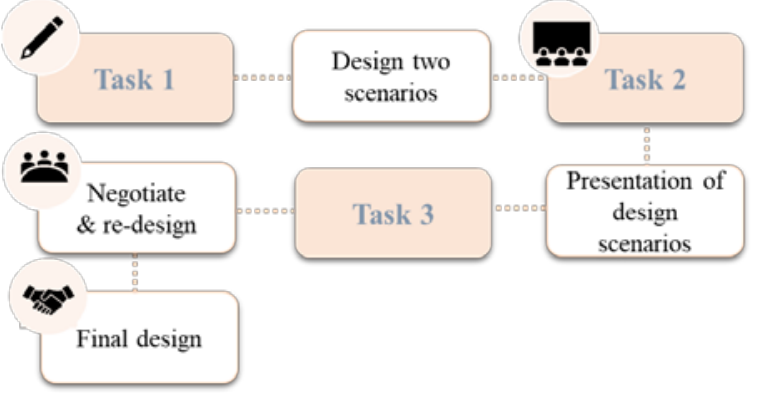

Figure 6. The AR sandbox experiment (Phase 1- scenario design)

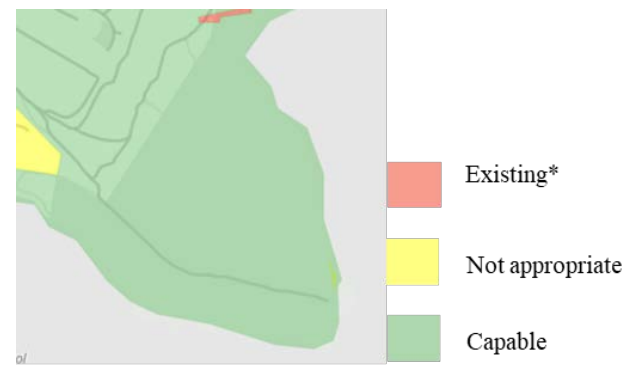

Figure 7. The evaluation map of the active transport system Source: (Ballal n.d.) geodesign workshop Sydney 2016.

*More details on evaluation map are provided in (Pettit et al. 2017) 
They were divided into two teams of active transport and tourism; each team focused on the topics related to the theme. They were given some time to discuss, design, and negotiate among themselves about the location of trails in relation to the terrain, slope, scenic views, etc. to come up with one/two design ideas of trails for the tourism and active transport systems (Task 1). They were given the existing trail and the contour lines of the site. ArcGIS online was used at this stage and they were using the cruiser interactive tables (Cruiser Interactive 2018) for this exercise. They were then presented their scenario design to the other team (Task 2). After negotiations with the other team they ended up with a final trail design (Task 3- Figure 8). The scenario design from phase 1 was downloaded as a shapefile and then was exported into GrassGIS (GRASS GIS 2018) as an input for phase 2 .

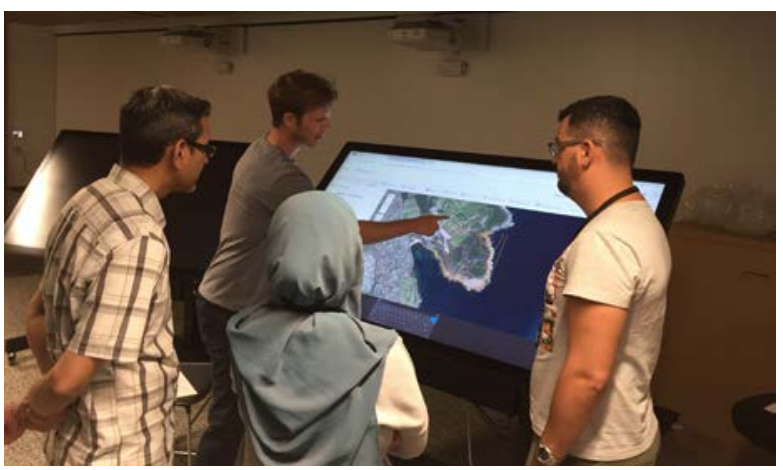

Figure 8. Phase1, task 3: Participants were negotiating and using the multitouch screen tables available at CAL (UNSW Built Environment 2018)

In phase 2, sandbox, participants were asked to build a model of the final scenario design from phase 1 onto the sandbox surface displaying the trails of the current terrain. Using their hands forming their design on the sand, participants were engaged and interacted with each other during this experiment. The experiment included six tasks (Figure 9). Prior to running the experiment, participants were first briefed with the basic geographic science. They were introduced contour lines and topographic and elevation maps; for example, closer contour lines represent steep slope and the wider contour lines are spaced from each other, the gentler is the slope. The first task was think aloud and explore the concept of elevation (National Science Foundation n.d.). They were asked to get familiar with the colour changes of the elevation map as they modify the sand surface.

For the second task, participants were given the topographic data and contour lines to build the site (Figure 10a). Digital Elevation Model (DEM) 5 meter Grid of Australia was downloaded from ELVIS (Australian Government (GeoScience Australia) 2018) for extracting the contour lines of the selected study area. Contour lines were extracted from DEM using Spatial Analyst (ESRI 2017) and were then projected onto the sandbox for participants to build the topographic site. Third task was to build and transfer the design from phase 1 onto the surface of the sand. The scenario design from phase 1 , which has been already imported into GrassGIS was displayed on the sandbox for participants to build it (Figure 10b). Participants were given some tools and scaled models such as trees, 3D printed buildings and people to use in their design. Although it was a trail design, they decided to give access to cars to reach the Malabar headlands for disabled users. Car park and the road are displayed on Figure 12.

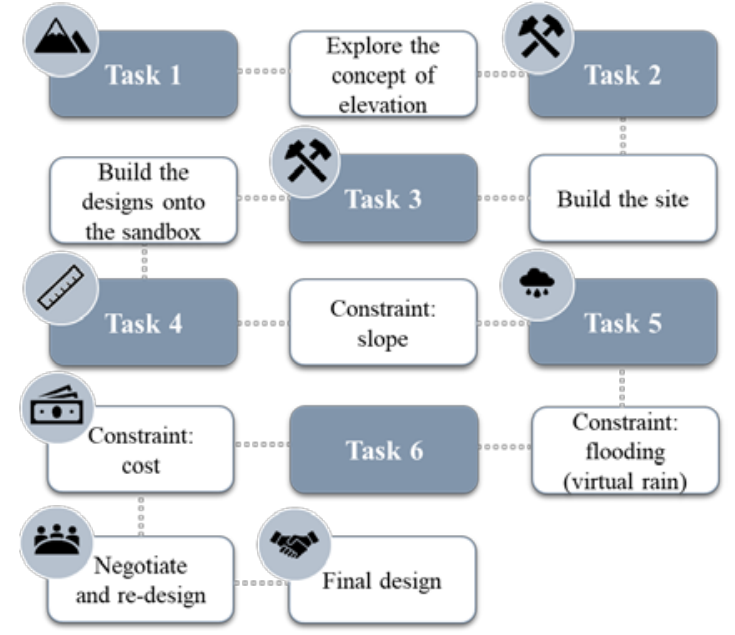

Figure 9. The AR sandbox experiment (Phase 2 - Sandbox)

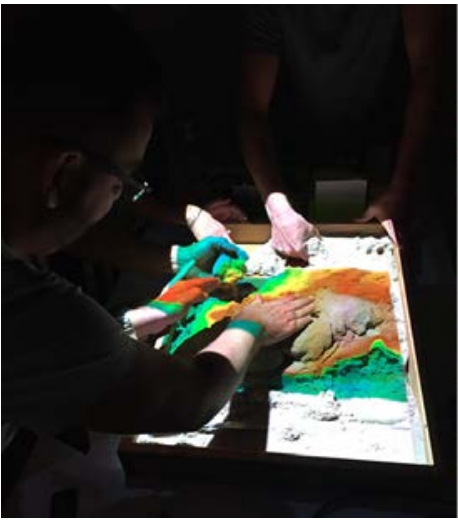

(a)

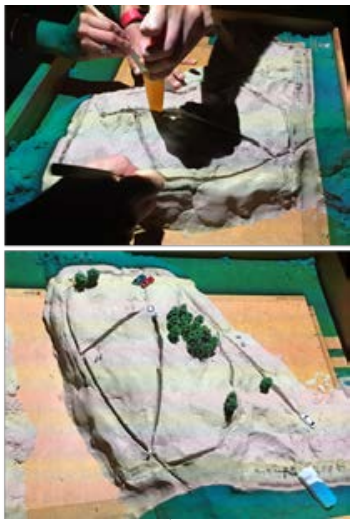

(b)
Figure 10. a) task 2, participants are building the topographic site; b) task 3, participants are transferring their trail design onto the sandbox

In the fourth task the first constraint was introduced (Figure 11a). Participants were first asked to predict that on which landform the erosion will be stronger. Although they did not have access to all the information related to erosion such as soil type, and vegetation type, they were briefed that the steeper the slope, the stronger erosion and deposition can occur because of the speed of water which can carry more stuff in a higher speed (National Science Foundation n.d.). Then they were asked to design on a slope less than 5 degree (Figure 11b). Slope tool (Spatial Analyst) was used to create a slope raster file of the case study and was projected onto the sandbox for this task. They were given some time to negotiate and come up with the best design option, which in this exercise is the design with the lowest impact on erosion on the slope less than 5 degrees.

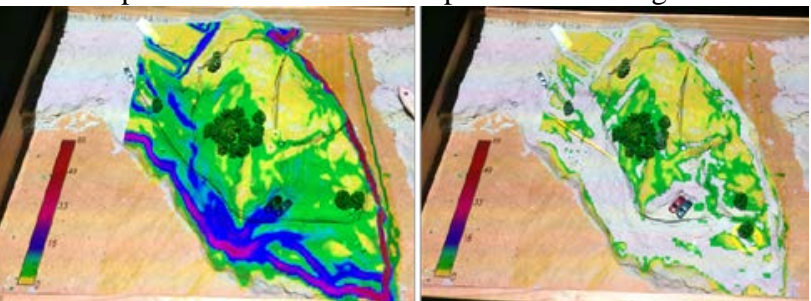

Figure 11. a) task 4, slope map; b) task 4, slope map restricted to $0-5$ degrees

The fifth task was to test flooding. The second constraint was introduced in this task. Virtual water was added to the map and 
they were asked to observe where water flows and do any required changes to reduce potential flooding-related issues (Figure 12). At this stage, the participants added a bridge to the design in order to avoid flooding. This is represented by a yellow line in Figure 12. They used the terrain to identify the location of the bridge which might not be possible with 2D maps.

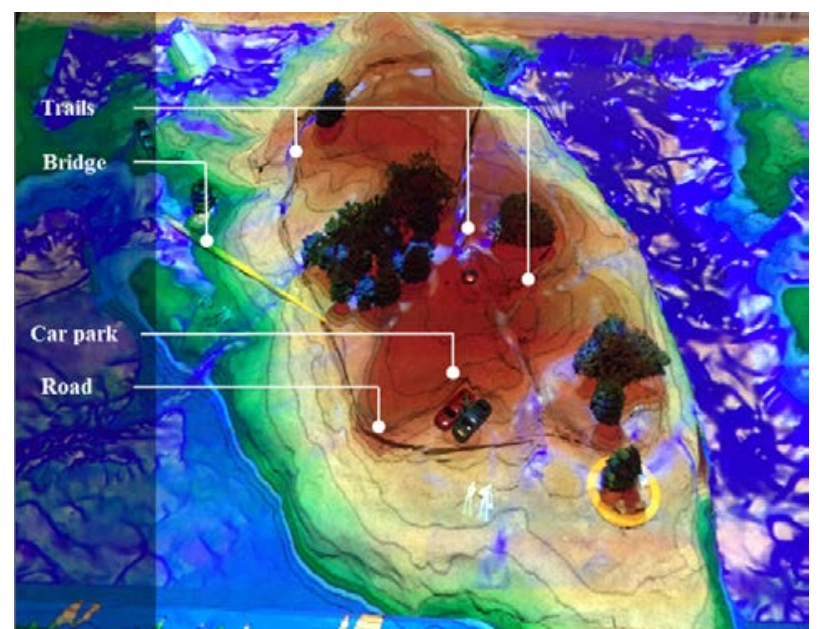

Figure 12. Task 5, virtual water was displayed on the site

Task 6 introduced a constraint of cost. They were given a certain budget for this task and were only allowed to build $5 \mathrm{~km}$ of the trail (Figure13a). Scale bar was added to the map for this task to measure the trail. Participants were given some time to negotiate and come up with the final design (Figure 13b). However, they did not change the design at this stage because the cost was already in limits. This shows that there needs to be a more aggressive cost in the future experiment, so they will be forced to change the trail. At the end of the experiment, participants received a link to the online questionnaire to fill.

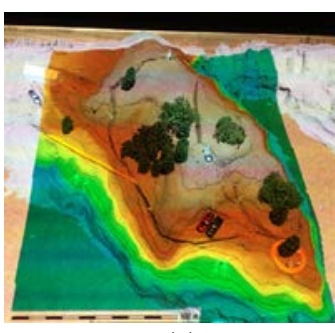

(a)

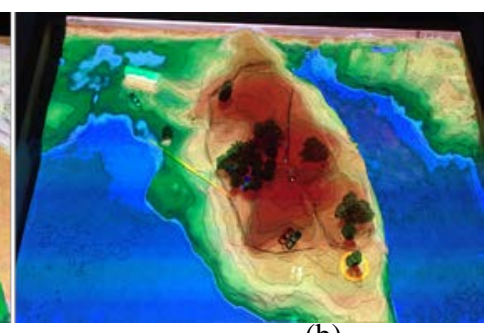

(b)
Figure 13. a) task 6; b) Final design

\section{RESULTS}

This section describes the results of the online questionnaire. We are not interested in assessing the final design in terms of landscape architecture and/or urban planning. The questionnaire provides information about the usability of the AR sandbox and its performance in terms of decision-making, prioritizing design interventions, and negotiations among team members for the trail planning task in this paper.

\subsection{Online questionnaire}

An online questionnaire was designed with a total number of 17 questions for this experiment. The questionnaire composed of five sections. The first section included general questions regarding age range and the professional background and the field of study of the participants. The second section was named "sandbox usability". Six questions were designed for this section to query the usability of the sandbox. The rest of the sections were "decision-making", "prioritizing design interventions", and "negotiation", respectively. At each of these sections participants were asked three questions in accordance with the abovementioned sections.

4.1.1 Sandbox usability: Sandbox usability questions revealed the benefits and limitations of utilising this tool. Participants were all able to recreate the terrain easily on the sandbox (\%100). They all rated the use of sandbox as "somewhat easy" for trail planning (\%100). In addition, participants ranked their preference in drawing design concepts. The first preference was designing on paper (66.6\%), second preference was using digital maps (66.6\%). The AR sandbox was ranked equally for the three preferences (33.3\% for first, second, and third priority). Respondents were "extremely satisfied" to utilize the AR sandbox in the design stage. They found that the AR sandbox was running very quickly and was very practical for understanding the design. Selections of respondents' comments are presented below:

\section{Respondent 1. Users can "quickly see potential conflicts between ideas and landform and drainage"'.}

\section{Respondents 4. "Interactivity and quick visualisation of changes" is the main benefit of using the AR sandbox in the design process.}

While participants rated AR sandbox as a useful tool, they mentioned some limitations and difficulties in using the AR sandbox such as the scale of the trails which required to be adjusted with the scale of the terrain. Although this stage was done using GrassGIS, because it took some time participants mentioned it as one of the limitations of the AR sandbox. Participants were also concerned about the accuracy of the model which was moulded on the AR sandbox in terms of elevation.

4.1.2 Decision making: All the four participants responded positively to the question asking if AR sandbox helped them understand the design (\%100). Responses revealed that the AR sandbox was "extremely useful” (\%75) and "very useful” (\%25) when making decisions during the design process. Participants were also asked to mention what other data or information they needed to make decisions about trail design and where to put the trail. Respondents included local ecology, water-related data, budget, existing facilities and contours, site context, user desires, and environmental constraints.

4.1.3 Prioritising design interventions: All participants were able to prioritise different design interventions and ideas using the sandbox (\%100). They were "extremely satisfied" (\%75) and "very satisfied" (\%25) in utilizing the AR sandbox in prioritising design ideas during the experiment. Participants commented that the AR sandbox helped them to understand the site better, visualise vantage points, address some issues such as drainage problems, and allow them to quickly negotiate and redesign. 
4.1.4 Negotiation: All participants were able to negotiate their ideas among their peers using the AR sandbox (\%100) and were all "extremely satisfied" (\%100) with using the AR sandbox in providing a negotiation space between team members. In responding to the question regarding how the AR sandbox helped them to negotiate with their team members, they mentioned that the AR sandbox "encouraged discussion" (Respondent 1), "allow practical changes in short time" (Respondent 2), enabled everyone to "touch the sandbox at the same time" (Respondent 3), and allow them to "quick[ly] try [different] ideas and visualise results” (Respondent 4).

\section{DISCUSSION}

The results of the questionnaire and the experiment itself suggested the usability of the AR sandbox in trail planning. The results revealed what type of data is required for such an experiment in a larger scale. The capabilities and limitations of the AR sandbox resulted from this experiment are summarized in Table 1. The main demerits in the trail planning experiment were the export functionality of the AR sandbox and matching the scale of the final design of phase 1 onto the sandbox for casting. These factors limited the authors to export the final design into GIS environment for further analysis. If the export function is added to the AR sandbox, users could assess how close is the moulded design to the existing Digital Elevation Models (DEM) to address the accuracy issue. In addition, the calibration of the AR sandbox, is a time-consuming process. One solution for this is to set up the 3D scanner and the projector on the fixed customized table attached to the sandbox which seems to be already utilised at some centres such as UC Davis (Kreylos 2018b).

On the other hand, the AR sandbox was found to have many merits in support of collaborative planning, decision-making, communication and participant engagement. It is most effective when the AR sandbox is being used to understand the topography of the case study with considerable differences in elevation rather than being used on a flat site.

In addition, the authors believe that the AR sandbox experiments can help improving different models of the geodesign structure including: representation, process, change, and decision models. Table 1 shows the capabilities and limitations of the AR sandbox resulting from the trail planning experiment.

\begin{tabular}{|c|c|}
\hline \multicolumn{2}{|c|}{ AR sandbox characteristics } \\
\hline Factors supporting trail planning & Factors restricting \\
\hline & trail planning \\
\hline -Effective technique for moulding and & -Exporting the design \\
\hline casting models & \\
\hline -Collaborative decision-making capability & -Scale-related issues \\
\hline -User interaction and experience & -Topographic-related \\
\hline & accuracy of the \\
\hline & moulded design \\
\hline -Quick and simultaneous demonstration of & -Time-consuming \\
\hline design changes on the sand & calibration process \\
\hline -Detecting flood prone areas & \\
\hline -Understanding topography & \\
\hline -Understanding slope & \\
\hline -Cost-effective design & \\
\hline -Prioritizing design interventions & \\
\hline -Better understanding the context & \\
\hline -Ability to project different GIS data onto & \\
\hline the sandbox & \\
\hline
\end{tabular}

Table 1. factors supporting and restricting trail planning using AR sandbox
It was found that AR sandbox is a great tool for the visualisation of data, particularly topographic, landscape, and watershed-related data. Therefore, it could help the representation model and the process model of geodesign structure in order to better understand the study area. It can also help the change model by displaying the changes of the design on the sandbox and examining the effect of the change on the context. Although the user can partially envisage impacts of the design, the AR sandbox cannot be a reliable tool for assessing impact models because of lack of simultaneous analyses of the site. However, it can be used for decision models where the final decision need to be made. This assertion need to be further examined in a geodesign workshop using the AR sandbox.

\section{CONCLUSION AND FUTURE WORK}

This paper describes a trail planning exercise, which is based on Steinitz (2012) geodesign framework. An AR sandbox is used in this paper in order to assess its implications in the geodesign workflow for the first time. Two systems of active transport and tourism were selected from a geodesign workshop which was held in Sydney Australia in 2016. A smaller scale site was selected from the previous geodesign case study boundary. An experiment was conducted at two phases of scenario design and sandbox with four participants. The outcome of phase 1 was a trail with specific focus on active transport and tourism. This design intervention was then moulded onto the sandbox and three constraints of slope, flooding, and cost were introduced to participants. They modified the design intervention in accordance with the constraints mentioned above. Lastly, the final design was displayed on the sandbox (Figure 12b).

In its current form, the AR sandbox managed to successfully create both an educational learning environment and design environment by offering the necessary tools for visualisation, communication, decision making, and interaction between the team members, as well as prerequisites for the simulation of the site. However, the AR sandbox has the potential to be enriched with some features and tools such as export, and scale functionalities. These additional features could assist in the design conceptualisation as part of a geodesign workshop. Currently, the export function is limited to scan the sandbox model using complex python scripts in the GrassGIS environment (GRASS GIS 2018). Therefore, the export function would be useful in order to provide flexibility for further analyses on the exported model in a GIS environment. Furthermore, the scale of the design was difficulty matched with the sandbox. Additional import extension formats to GrassGIS compatible with other GIS software could address this issue such as the GeoJSON format. The incorporation of these suggestions will lead to a more comprehensive, AR sandbox tool which can support both educational and practical applications. Results also show that geodesignhub and AR sandbox can act as Planning Support (PSS) tools by facilitating discussions around scenario planning and creating new design interventions around planning challenges (Pettit et al. 2018). However, this needs to be further examined in a more complex planning challenge.

We acknowledge the limitations of the AR sandbox experiment in this paper. Because it was a trial experiment a limited number of participants were recruited. This could trigger a response bias. Moreover, the phase 1 of the experiment was not conducted during a geodesign workshop neither participants were interacting with the geodesignhub software. Therefore, we suggest running a full experiment during a live geodesign 
workshop with a larger cohort of respondents, ideally exceeding 30. It is also suggested that such an exercise should be accompanied by interviews or a focus grouped discussion. This will be pursued in future research. Finally, future work can compare AR sandbox with different AR and VR devices and their implications in PSS.

\section{ACKNOWLEDGEMENTS}

We would like to acknowledge Oliver Kreylos for the open source AR sandbox scripts, and Carmela Ticzon for her support in providing the geodesign workshop materials.

\section{REFERENCES}

Australian Government (GeoScience Australia), 2018. ELVIS. Elevation Information System. http://www.ga.gov.au/elvis/.

Ballal, H., n.d. Geodesign Hub. Dublin, Ireland: Geodesign Hub Pvt. Ltd. https://www.geodesignhub.com/, (28 February 2018).

Ballal, H., 2015. Collaborative planning with digital design synthesis. Doctoral thesis. University College London, London. http://discovery.ucl.ac.uk/1471177/1/HB-Thesis-Master.pdf, (7 March 2018)

Cruiser Interactive, 2018. Informing sharing reinvented. Australia. https://www.cruiserinteractive.com.au/, checked on (5 March 2018).

ESRI, 2010. Changing geography by design. Selected readings in GeoDesign. United States of America.

ESRI, 2017. ArcGIS Desktop 10.5. Redlands, CA.

GRASS GIS. Version 7.4.0, 2018. GRASS Development Team. http://grass.osgeo.org/, (1 March 2018).

Haddad, M. A., 2015. A Framework for Geodesign: Changing Geography by Design SteinitzCarl, 2012. Redlands, CA: ESRI Press. 208 pp. ISBN 978-1-58948-333-0. In Journal of Planning Education and Research 35 (2), pp. 228-230. doi: 10.1177/0739456X15581606.

Jenkins, H.S.; Grant, R.; Hopkins, D., 2014. Shifting Sands and Turning Tides. Using 3D Visualization Technology to Shape the Environment for Undergraduate Students: American Geophysical Union, 12.

Jiang, L.; Masullo, M.; Maffei, L.; Meng, F.; Vorländer, M., 2018. A demonstrator tool of web-based virtual reality for participatory evaluation of urban sound environment. In Landscape and Urban Planning 170, pp. 276-282. doi: 10.1016/j.landurbplan.2017.09.007.

Kreylos, O., 2018a. AR Sandbox. http://idav.ucdavis.edu/ okreylos/ResDev/SARndbox/, (8 May 2018).

Kreylos, O., 2018b. Augmented Reality Sandbox. News. The University of California. https://arsandbox.ucdavis.edu/info/media/, (3 May 2018).

Kreylos, O.; Kellogg, L. H.; Reed, S.; Hsi, S.; Yikilmaz, M. B.; Schladow, G. et al., 2016. The AR Sandbox. Augmented Reality in Geoscience Education. In American Geophysical Union.

http://adsabs.harvard.edu/abs/2016AGUFMED51H0843K, （1 March 2018).
Liben, L.S., 2007. Education for Spatial Thinking. In William Damon, Richard M. Lerner (Eds.): Handbook of Child Psychology. Hoboken, NJ, USA: John Wiley \& Sons, Inc.

McHarg, I.L., 1969. Design with nature: Garden City, NY: Natural History Press.

Miller, W.R., 2012. Introducing Geodesign. The concept. California, USA: ESRI.

National Science Foundation, n.d. Shaping Watersheds. Augmented reality Sandbox Facilitator's Guide. https://arsandbox.ucdavis.edu/wpcontent/uploads/2016/11/Shap ing-Watersheds-AR-Sandbox-Facilitation-Guide.pdf, (1 March 2018).

NCSU GeoForAll Lab, 2016. Tangible landscape. https://tangible-landscape.github.io/index.html, (1 March 2018).

Nyerges, T; Ballal, H; Steinitz, C; Canfield, T; Roderick, M; Ritzman, J; Thanatemaneerat, W., 2016. Geodesign dynamics for sustainable urban watershed development. In Sustainable Cities and Society 25, pp. 13-24. doi: 10.1016/j.scs.2016.04.016.

Petrasova, A.; Harmon, B.; Petras, V.; Mitasova, H., 2015. Tangible Modeling with Open Source GIS. Cham: Springer International Publishing.

Pettit, C.; Widjaja, I.; Russo, P.; Sinnott, R.; Stimson, R.; Tomko, M., 2012. Visualisation support for exploring urban space and place. In ISPRS Ann. Photogramm. Remote Sens. Spatial Inf. Sci. I-2, pp. 153-158. doi: 10.5194/isprsannals-I-2153-2012.

Pettit, C.; Bakelmun, A.; Lieske, S. N.; Glackin, S.; Hargroves, K. C.; Thomson, G. et al., 2018. Planning support systems for smart cities. In City, Culture and Society 12, pp. 13-24.

Pettit, C.J, Hawken, S, Ticzon, C., 2017. Sydney Geodesign Workshop 2016: Developing a framework for collaborative multi-agency scenario planning, UNSW, Sydney. doi:10.4225/53/5a8dfd09de724.

Rivero, R.; Smith, A.; Ballal, H.; Steinitz, C., 2015. Promoting Collaborative Geodesign in a Multidisciplinary and Multiscale Environment. Coastal Georgia 2050, USA. In: Peer reviewed proceedings of Digital Landscape Architecture 2015 at Anhalt University of Applied Sciences. Berlin: Wichmann, pp. 42-58. http://gispoint.de/fileadmin/user_upload/paper_gis_open/53755 5005.pdf, (7 March 2018).

Steinitz, C., 2012. A framework for geodesign. Changing geography by design / Carl Steinitz. Redlands, Calf: ESRI.

System 76, 2018. Do it yourself. Augmented reality sandbox. https://system76.com/weekend project/arsandbox, (26 February 2018).

UC Davis, 2016. 3D interactive dynamic. Powerful education tool. https://arsandbox.ucdavis.edu/, (1 March 2018).

UNSW Built Environment, 2018. City Analytics Lab (CAL). UNSW Sydney. https://www.be.unsw.edu.au/content/cityanalytics-lab, (12 May 2018). 